\title{
E-learning Concept for the Properties of Materials Remote Study
}

\author{
Peter Arras ${ }^{1}$, Galyna Tabunshchyk ${ }^{2}$, Tomaš Kozík ${ }^{3}$ \\ ${ }^{1}$ Department of Engineering Technology, Thomas More university college, Belgium, Sint Katelijne Waver, J. P. De \\ Nayerlaan 5, E-mail: peter.arras@lessius.eu, URL www.thomasmore.be \\ ${ }^{2}$ Assoc.Prof. of Software Tools Department of Zaporizhzhya National Technical University, Zhukovskogo, 64, \\ Zaporizhzhya, 69063, Ukraine, galina.tabunshchik@gmail.com, URL www.zntu.edu.ua \\ ${ }^{3}$ Prof. Ing. DrSc, Department of Technology and Information Technologies, Faculty of Education, Constantine the \\ Philosopher University in Nitra, Dražovská 4, 94901 Nitra, URL www.ukf.sk
}

\begin{abstract}
This paper describes how remote and virtual laboratories can support students in material properties study. The structure of the course and division of the study materials are described. The educational environment used for virtual and remote laboratories is presented.
\end{abstract}

Keywords—remote laboratory; virtual laboratory; material stiffness, shape stiffness

\section{INTRODUCTION}

The question of virtual and remote labs development and integration in common e-learning infrastructure is very popular last year's [1] [2]. But experience has shown that every educational technology needs to be coupled with appropriate pedagogy.

The second point is that the mostly all remote laboratories are developed for studying in electrical engineering [3] and control engineering [4]. Remote labs concerning mechanical experiments are scarce due to complexity of structures, and because these processes are more difficult to control in an electronically or electrical manner.

Many engineering and science studies, including on material sciences, are based on theoretical knowledge. Engineering students nevertheless also need a lot of practical work/laboratories to acquire the knowledge and skills in procedures they will have to use in their professional career. Since time and other resources are limited to make available real life infrastructure in a classroom teaching environment, the introduction of a remote and virtual lab environment is considered as an efficient tradeoff between the necessity for lab work, and the above mentioned boundary conditions.

Because of the increasing popularity of the use of mobile devices in everyday life, it seems only natural to also optimize the e-learning infrastructure with additional applications for iOS and Android. This will make learning even more flexible and offer more time and space independent possibilities for students to use the labs and make it more appealing to students of nowadays digital era [5].
Besides that, the use of hypertext supporting learning materials in education, along with simulation examples explaining natural science phenomena or changes in the properties of materials under the influence of the defined external conditions, with the relationship to the applicability of remote experiments, has significant didactic benefits in education.

The lecturer (educator / teacher) can very flexibly use this instructional support at any stage of educational lessons. Without specific requirements for their modification, it can be advantageously used in the introductory - motivational - part of the lecture, but also in the final stage to summarize the most important conclusions of lecture together with setting the control tasks.

There is also another pragmatic reason for expansion of the use of remote and virtual laboratories in higher educational courses. At present, the lecture halls are already equipped with modern information and communication technologies such as large screens or interactive whiteboards, which provide seamless sharing of information at a high quality without limitation of the number of students in the auditorium.

\section{STUDY APPROACH FOR NEW MATERIALS}

The field of material science is defined as a key knowledge area for engineers. Many - if not all innovations in modern technologies are related to the use of new materials, or new technological methods of using existing materials. However, study time in curricula is limited and new findings cannot be fitted in. E_learning modules could help make up for this lack of time. This paper devoted to the construction of a virtual and remote laboratory which should help students to understand the difference between material and shape stiffness. It should be the first in a series of labs on basics of material sciences to optimize available time in real laboratories, so the real lab can be used for more complex experimenting. Some examples of remote labs investigating Young's 
modulus can be found [4]. Goal of this lab is rather to find Young's modulus as a pure material characteristic.

For all students, hands on experiences are important to deepen their knowledge in the topics they learned during lections. Combining virtual simulation and distance handling remote laboratory we want to imitate the real educational process with an individual and hands on approach.

The setup of our approach in materials teaching is a blended learning approach. There is an hypertext supported learning environment which explains the theoretical basis of the phenomena, shows examples of it, and links to literature to on the subject. The theory itself is then supported with real physical lab sessions, a virtual laboratory to let students experiment on the phenomena in a extensive way, and a remote laboratory is installed and used by students to check the theory with real data and to give the feeling of connection to reality.

The hypertext supported material is used during the classroom teaching lessons on material sciences and afterwards by students for self-study. It contains all materials, slides etcetera used in the lessons. It also contains instructions, assignments and help for the real life material tests in the lab. (Including tensile testing, hardness tests, microscopy). As such the e_learning part enables students to study the course in one clearly defined manner: the look and feel of classroom teaching is the same as the look and feel of the self-study part. This will increase efficiency of the self learning.

The remote laboratory is an automated real laboratory (experiment) in which students can experiment themselves to find out about the laws of nature of other phenomena. The access to the laboratory is over the internet, with no need for manual interference.

The virtual laboratory is a simulation of a laboratory in which students can experiment with simulated experiments.

Assessment of the students is made dependent on the students role. If student/experimenter is a regular student, evaluation is done based on the reports they turn in on their assignments and by means of a formal exam. The hypertext supported method for them is a way of studying. If student/experimenter is an interested knowledge seeker, he she will be able to use to hypertext supported materials to broaden his knowledge, which he can evaluate by means of question lists in the e_learning environment.

\section{STUDY PHENOMENON}

The theoretical content/phenomenon studied is the difference between shape and material stiffness.

Stiffness of a construction is an important feature in mechanical and construction design. Not only pure strength of the construction (resistance to rupture failure) is decisive for a construction, but often deformation of a design can undermine the usefulness and efficiency of the design. The characterization of the resistance to deformation is function of material parameters (material stiffness) and structural design parameters (shape stiffness). This difference seems to be a difficult concept for pupils/students to understand. As such it is valuable to organize a virtual and remote laboratory on it.

In the remote and virtual lab, students should study the theoretical laws on the behavior of structures (by means of cantilever beams) and its relation to shape and material. This is done in the hypertext environment. To illustrate the ruling theoretical laws, the virtual laboratory allows students to calculate different beam shapes, in combination with different materials to find the mechanical values (deflection, bending stress) that are important to define stiffness of the construction.

They can check and determine in the remote laboratory how all of this is related to reality.

Standard formulas can be used to determine deflection (fig. 1) and stresses [6].

Maximum deflection at the free end:

$$
y=\frac{F \times L^{3}}{3 \times E \times I}
$$

Maximum bending stress in the cantilever beam (at the supported end):

$$
\sigma=\frac{F x L}{I / v}
$$
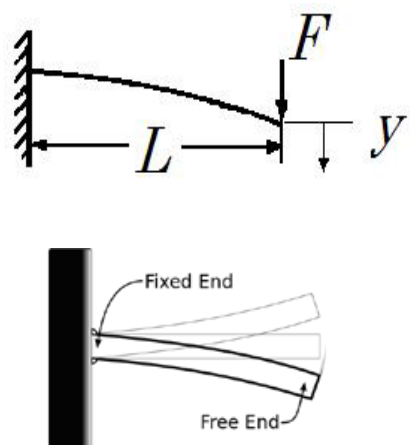

Figure 1.

Deflection of a cantilever beam.

Moment of inertia (I): e.g. of a rectangle:

$$
\mathrm{I}=\frac{\mathrm{b} \times \mathrm{h}^{3}}{12 \times \mathrm{I}}
$$

TABLE I. USED SYMBOLS

\begin{tabular}{|l|l|l|}
\hline \multicolumn{3}{|c|}{ Used symbols } \\
\hline \multicolumn{1}{|c|}{ Symbol } & \multicolumn{1}{|c|}{ Name } & \multicolumn{1}{c|}{ Unit } \\
\hline $\mathrm{E}$ & Young's modulus & $\mathrm{MPa}$ \\
\hline $\mathrm{I}$ & Moment of inertia & $\mathrm{mm}^{\wedge} 4$ \\
\hline $\mathrm{F}$ & Load & $\mathrm{N}$ \\
\hline$\sigma$ & $\begin{array}{l}\text { Maximum bending stress in the } \\
\text { cross-section }\end{array}$ & $\mathrm{MPa}$ \\
\hline $\mathrm{y}$ & Maximum deflection & $\mathrm{mm}$ \\
\hline $\mathrm{L}$ & Length of beam & $\mathrm{mm}$ \\
\hline
\end{tabular}




\begin{tabular}{|l|l|l|}
\hline $\mathrm{v}$ & Distance to neutral fiber & $\mathrm{mm}$ \\
\hline
\end{tabular}

IV. VIRTUAL LABORATORY

The virtual laboratory is a simulation of a laboratory for material properties study. It was constructed using the basic formulas. Only limitation with these formulas is that asymmetrical test specimens will yield erronous values, because bending outside the plane of the specimen is not considered. In the virtual lab a number of specimen with standard sections can be tested.

A. Functional requirements for the virtual lab:

- Calculation and visualization of the deflection of a beam, with measurement of deflection at the end and indication of maximum stress and force. Equations used you find above.

- The values for different Young's modulus for a variety of materials should be chosen according to reported values [7] .

- $\quad$ For a variety of shapes (rectangular section, Hbeams, U-beam, hollow shapes...) = shape stiffness.

- For different orientation of the same shape (increment angles $1^{\circ}$ ) about the principal axes.

- $\quad$ For a variety of dimensions in the same shape. (cross section dimensions and length). The different values should be entered by the student experimenter.

\section{B. Supplementary Requirements for the virtual lab.}

Experimenting student should be able to select all different possibilities with the aid of pull down menus and selection panels, and dialogue boxes for dimensions.

Readings of deflection, force and stresses with the aid of lookalike analogue meters.

Force should be applicable with the aid of a slider bar, and real time adjustment of readings should be taken care of.

Readings should be exportable: available in a window from which to copy, together with material and cross section data. This feature is necessary for the students to make their reports. As such they can copy the data without retyping, but also without any special formatting in the virtual lab, so it can be fit in any report.

\section{Requirements for software}

For the virtual lab the simulation of the experiment uses HTML5, ActionScript and JavaScript. The component diagram of developed application is presented on the fig 2.

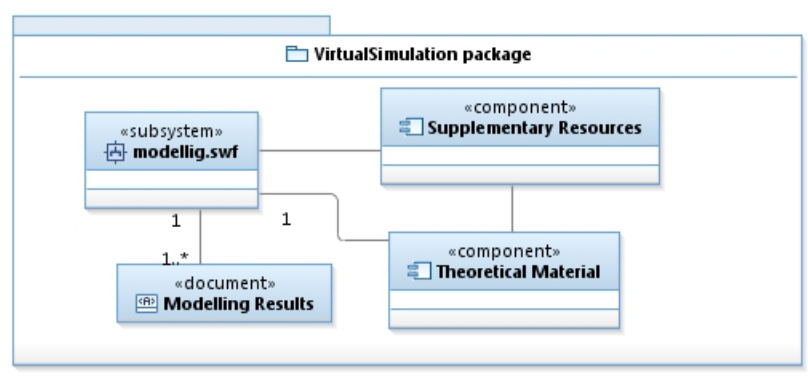

Figure 2. - Component Diagram for Virtual Lab

The realization of the calculation for different shapes is realized by classes put in package beam, which is part of subsystem "modelling” shown on the fig. 3 .

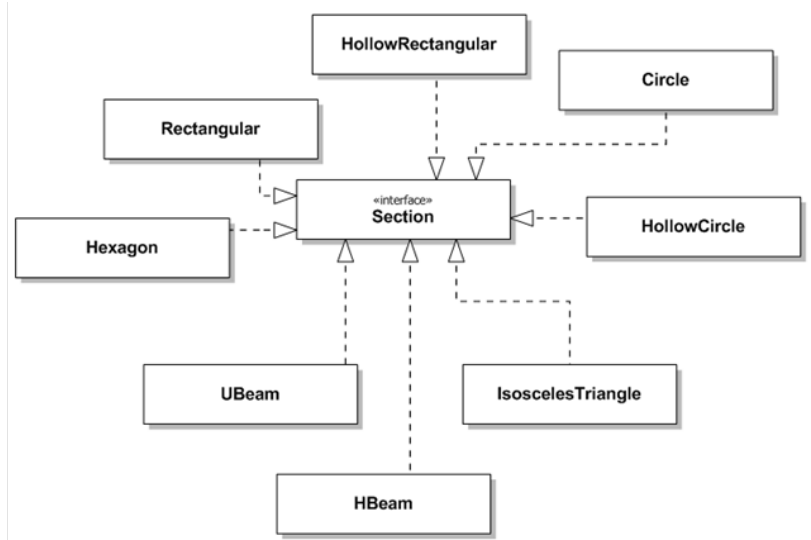

Figure 3. - Class Diagram for the cantilever beam calculation depending from the shap

\section{Virtual laboratory functionality}

To run the experiment on the client side user should use any web-browser with an installed flash player. The main screen of the virtual lab is in fig. 4.

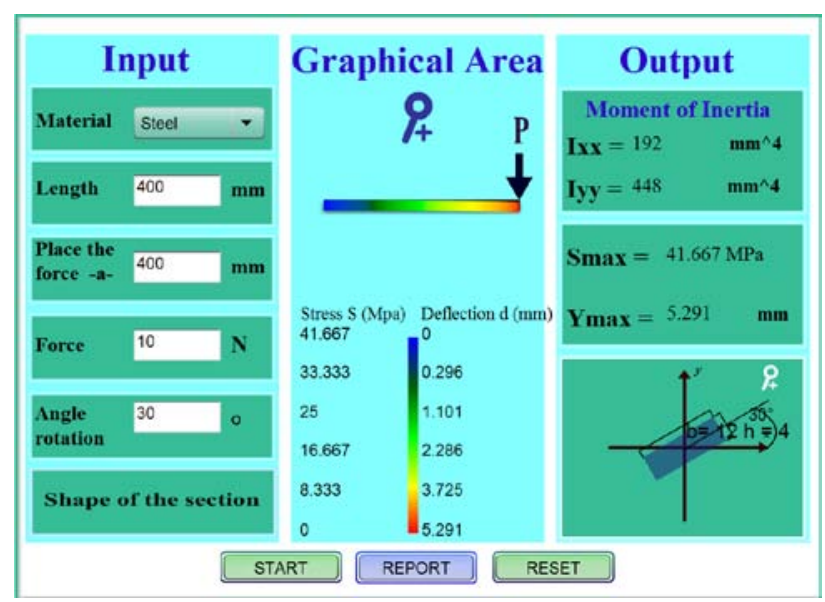

Figure 4. - Screen shot of the actual virtual lab. 
The results can be viewed in additional window and printed (fig. 5). The report window is a simple text window which allows the student/experimenter to copy paste these results in his lab reports, without having to type all texts.

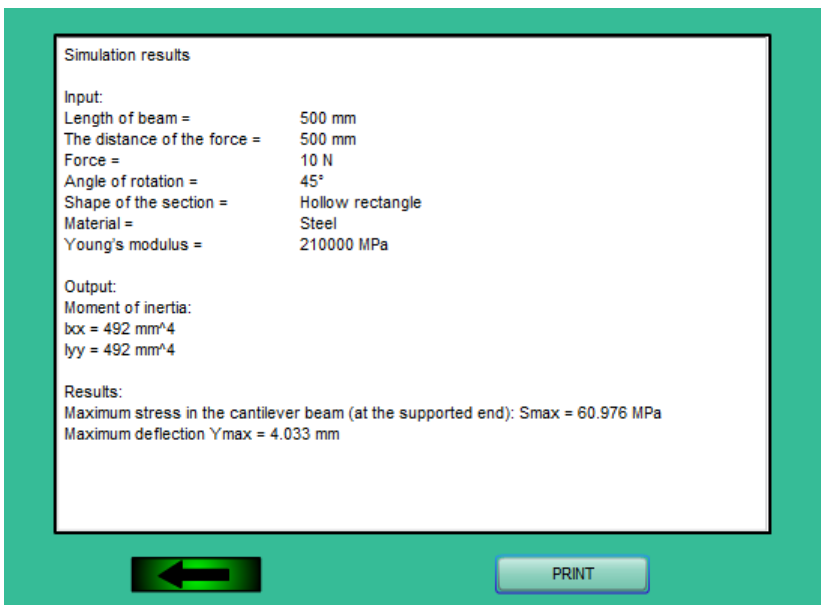

Figure 5. - Screen shot of the report screen.

\section{REMOTE LABORATORY}

The objective of the experiment to see the deflection of beams, and to measure the deflection itself [8]. These can be compared to the theoretical results from the virtual laboratory. The construction of the experiment consist of sets of beams. Essentially it are the same beams, rotated over $90^{\circ}$. The beams can be any basic shape (round, square, rectangular, hollow). The beams as deformed by pulling them with pneumatic cylinders (fig.6). A reading scale is attached to measure the deflection [8].

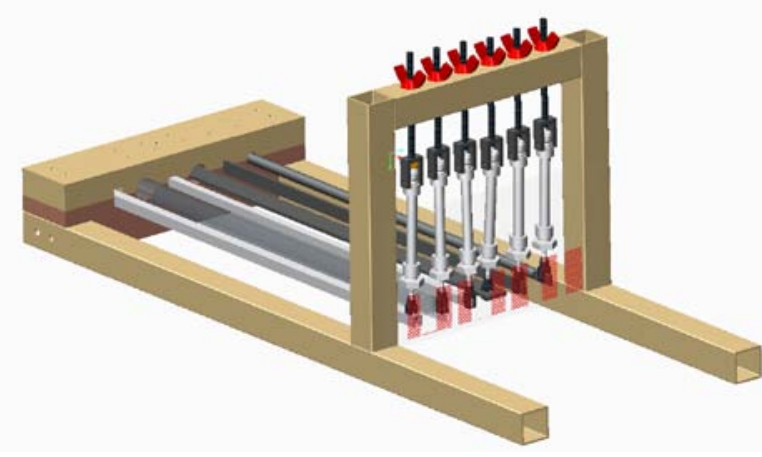

Figure 6. Practical arrangement of the remote laboratory setup

The experiment is constructed to test different materials. One of the materials is known to the user, and in the experiment will be used to show the difference between material and shape stiffness. The other materials are unknown to the user, but properties can be calculated with the knowledge and measurements of the known materials. The unknown material can then be determined in a table with material properties, and checked - if necessary - in the virtual laboratory.

User should also calculate for possible errors and influence of little differences in the data. Force exerted on the beams is dependent on the pneumatic pressure, so little differences can occur. It is therefore recommended to do the same experiment at least 3 times to find a reading, as is described in the experiment manual. Test specimens consist of round, square, rectangular and Ishaped profiles, made from different materials (steel, aluminum, copper, plastics), of which the section and section data will be reported on the experiment screen, to allow users to calculate the material properties.

\section{A. Hardware requirements}

The Remote lab infrastructure consists of following elements (fig. 7): server, relay board, 2 webcams (for viewing the experiment and measuring deflection).

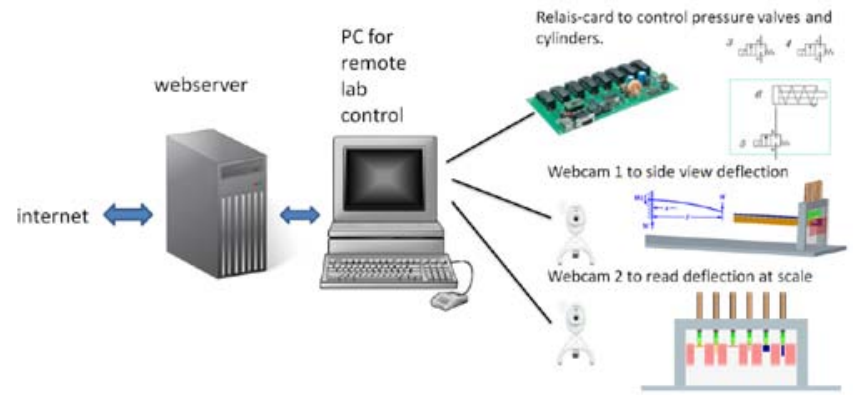

Figure 7. Installation of the virtual and remote laboratory setup.

The setup of the lab is consistent with other remote labs. Hardware setup of the experiment: the computer is driving a IO-board to control electro-pneumatic valves, and uses 2 cameras to see the deflection and measure deflection on the scale. Calculation of material properties (Young's modulus) is done by the experimentor himself. Choice was made not to automate this calculation, to stimulate self-study of the phenomenon, and to stimulate reflection on results (accuracy, influencing factors) by students.

Results can be cross-checked by recalculation of the results in the virtual lab.

Mechanical security is provided as the remote lab is only pressurised when in use.

\section{B. Software requirements}

Remote lab consists of several modules (fig. 8):

- module for cameras control (Server part Apache, PHP5, Red 5 Media Server, Client - webbrowser, Flash Player);

- $\quad$ module for board control;

HTML5); module for calculations (Javascript and

- $\quad$ portability on different platforms [1].

Security issues: the lab will check for abuse. Only a limited amount of experimenting time is awarded to each 
user. The software will check user IP-adress to control the available time. An experiment time of about 8 minutes per user should be enough. Software will also check for patterns in repeated activation of the pneumatic cylinders to avoid automated use of the lab.

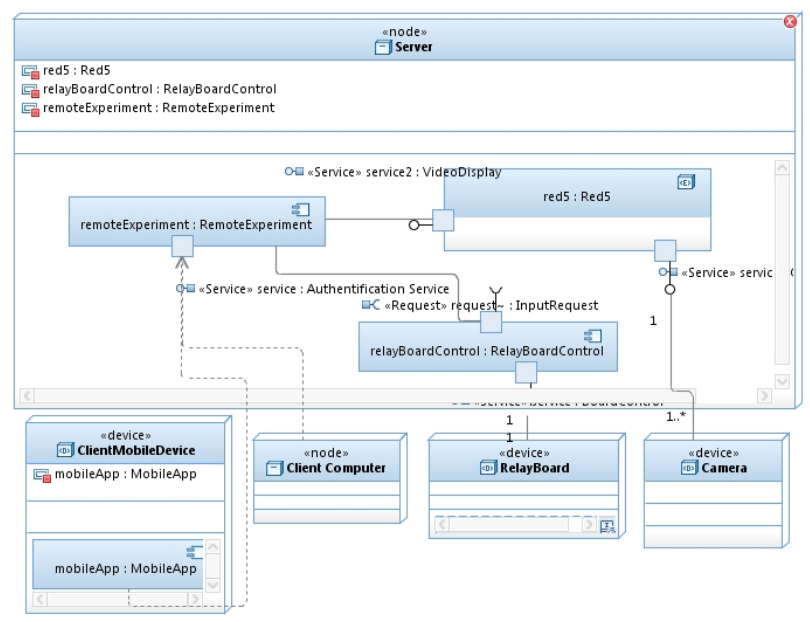

Figure 8. Topology Diagram for Remote Lab

\section{THEORETICAL SUPPORT FOR THE LABORATORY}

As it was decided the theoretical material was organized as hypertext (figure 9).

8. Materiaalkunde

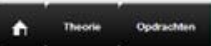

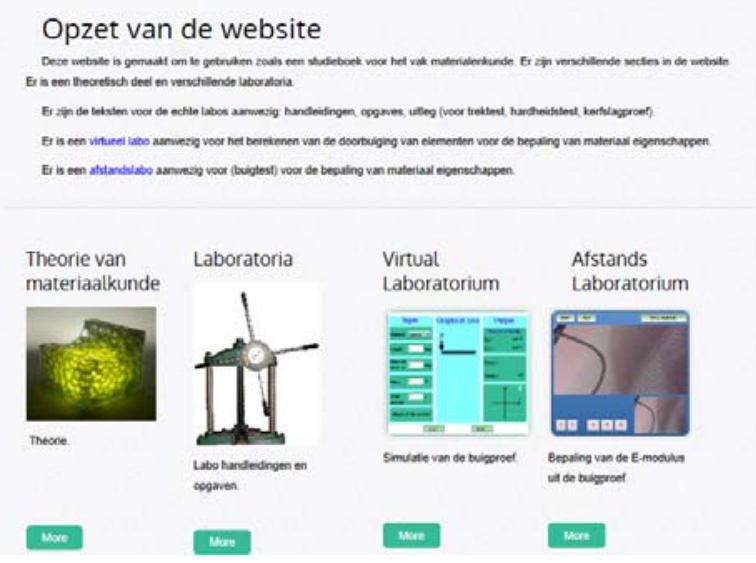

Figure 9. Main page of the hypertext environment

Next to the theoretical material there is a lot of emphasis on the different types of laboratory work, for real live testing, simulation and remote laboratory (fig. 10)

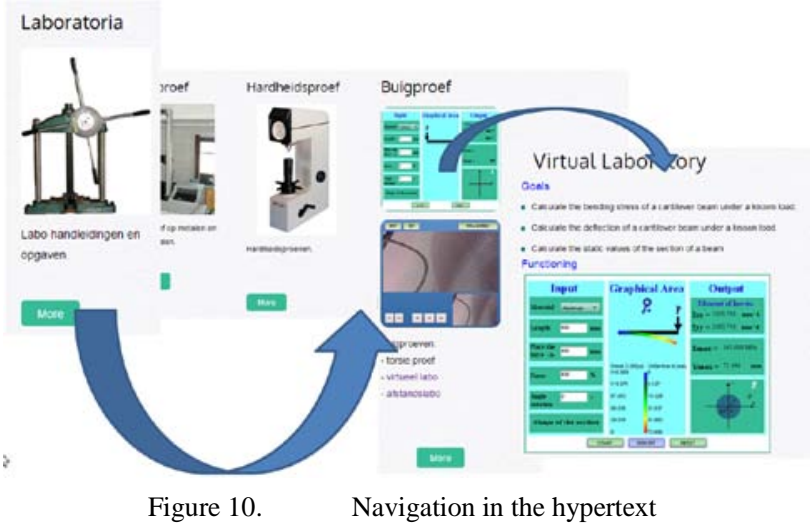

\section{USE OF THE COMPUTER AIDED LEARNING MODULE}

A complete driving learning module for material sciences is constructed. The structure of it can fount in fig. 10. It is the framework in which fits the theoretical courses, and the different laboratories described.

The CALM is intended to be used to study the phenomenon of material versus shape stiffness. The CALM contains all the learning contents students are supposed to study on the subject. The CALM will be used in classroom teaching and demonstrated to instruct students on how to use the remote lab. Students will study theory afterwards in their own pace, using the hypertext environment, and next simulate different combinations of materials and shapes in the virtual laboratory. Finally students can experiment on real material and shapes in the remote laboratory (Fig. 11).

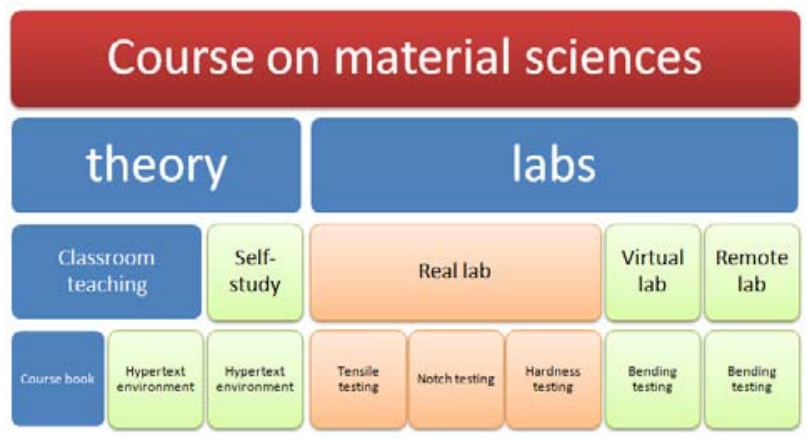

Figure 11. integrated in the CALM.

Structure of the course on material science,

In the remote lab a known material and shape is presented as a control to the theoretical formulas. An unknown material is also available. Task to students will be to determine the unknown materials, using the knowledge and relations between shape, materials and measurements they studied in the theoretical section and experimented in the real lab, the virtual (simulated) lab 
and in the remote lab. To check their work, a report on it should be made and sent in to the teacher. Detailed description of how and what the report should contain will be available in the hypertext environment. As such, the use of the remote lab will come close to the use of real life labs.

Intention is to use the lab in a blended learning environment, in conjunction with classroom teaching and physical labs for complex testing of material properties.

\section{SUMMARY}

In the paper an approach for material properties study with the use of CALM is described. It is based on the combination of theoretical knowledge in an hypertext driven environment, virtualization of the phenomenon and remote laboratory.

The CALM will be used to teach the material properties to bachelor students in engineering. After evaluation and comparing the results of the presented teaching approach to traditional classroom teaching, other complementary labs will be set up.

Learning objects are made browser and platform independent for portability to other than computer devices.

Future work is to combine requirements on remote and virtual labs for developing one system for creating an educational e-learning portal, including mobile applications for material sciences for engineers. Intention is to use the lab in a blended learning environment, in conjunction with classroom teaching and physical labs for complex testing.
[1] T. Kozik en M. Simon, „Preparing and managing the remote experiment in education.," in International Conference ICL IGIP 2012, Villach, Austria, 2012.

[2] G. Tabunshchik en A. Pritula, „Onthology of distance learning course," in Conference on Computer modelling and intellectual systems, Zaporizhzhya, Ukraine, 2007.

[3] E. G. Guimara, E. Cardozo, D. H. Moraes en P. R. Coelho, „Design and Implementation Issues for Modern Remote Laboratories,” IEEE transactions on learning technologies, vol. 2011, nr. Vol 4, No 2, pp. 149-161, 2011.

[4] GOLC, „Pt. Lab2Go,” GOLC (Global Online Laboratory Consortium), [Online]. Available: http://exp.fe.up.pt/lab2go/index.php/. [Geopend 1 May 2013].

[5] J. Unrein, „Promising new Tools for Developing M-learning.,” $T+D$, pp. 23-24, October 2011.

[6] R. C. Hibbeler, Statics and Mechanics of Materials, vol. Bending, New York: Pearson/Prentice Hall, 2004, pp. 511-544.

[7] M. F. Ashby, Material Selection in Mechancal Design, 3the edition red., Oxford: Elsevier Butterworth-Heinemann, 2005.

[8] P. Arras, „Construction of a remote laboratory aimed at augmenting knowledge on properties of materials," in International Conference on Interactive Collaborative Learning, Trnava, Slovak Republic, 2011. 